\title{
Global Perspective on Electric Vehicle 2020
}

\author{
Mr. Manas Agrawal ${ }^{1}$ \\ Mechanical Department \\ MGM's Jawaharlal Nehru Engineering College \\ Aurangabad, Maharashtra ,India
}

\author{
Mr. Mohammad Sufiyan Rajapatel ${ }^{2}$ \\ Mechanical Department \\ MGM's Jawaharlal Nehru Engineering College \\ Aurangabad, Maharashtra ,India
}

\begin{abstract}
In the present world where environment protection and energy conservation are major concerns, the development of hybrid vehicles and electric vehicles has taken an accelerated pace. The increasing interest in e-mobility and related developments has increased the need of academic and industrial involvement. This paper reviews the present status of electric and hybrid vehicles around the globe and the state of art technology and engineering. The need and importance of the collaboration of technologies of automobile, electric motors, drivetrains, batteries, electronics and controls, as well as, the need of collaboration between the government, industry, research institutions and electric power utilities are addressed. The challenges related to the infrastructure needed for the ease of use of electric vehicles is also mentioned.
\end{abstract}

Keywords-Electric Vehicles(EVs),Hybrid Electric Vehicles(HEVs), Electric Vehicle Index

\section{INTRODUCTION}

The way people and goods move is set to change dramatically over the next two decades, driven by a combination of policy, technology, economics, demographics and changing consumer preferences.

EVs first came into existence in the mid-19th century, when electricity was among the preferred methods for motor vehicle propulsion, providing a level of comfort and ease of operation that could not be achieved by the gasoline cars of the time. Modern internal combustion engines have been the dominant propulsion method for motor vehicles for almost 100 years, but electric power has remained commonplace in other vehicle types, such as trains and smaller vehicles of all types.

In the 21st century, EVs saw a resurgence due to technological developments, and an increased focus on renewable energy. A great deal of demand for electric vehicles developed and a small core of do-it-yourself" (DIY) engineers began sharing technical details for doing electric vehicle conversions. Government incentives to increase adoptions were introduced around the world. Electric vehicles are expected to increase from $2 \%$ of global share in 2016 to $22 \%$ in 2030.

The purpose of this paper is to describe the technology used in electric vehicles and their benefits over the traditional internal combustion engine vehicles. It also includes the challenges faced in driving the world towards e-mobility.

The paper begins with a review of the status of electric vehicles [EVs] and hybrid electric vehicles [HEVs] followed by the engineering philosophy of EV development. Subsequently it discusses the major technologies and finally the commercialization aspects.

\section{ELECTRIC MOBILITY IS ADVANCING AT A SPEEDY PACE}

In 2017, for the first time, global sales of new electric vehicles (EVs) passed a million units. Under the current growth trajectory, EV producers could almost quadruple that achievement by 2020 , moving 4.5 million units, around 5 percent of the overall global light-vehicle market. The annual passenger EV sales are expected to go up to 10 million 2025 , 28 million in 2030 and 56 million by 2050 .

\section{Global long-term passenger vehicle sales by drivetrain}

\section{Million vehicles}

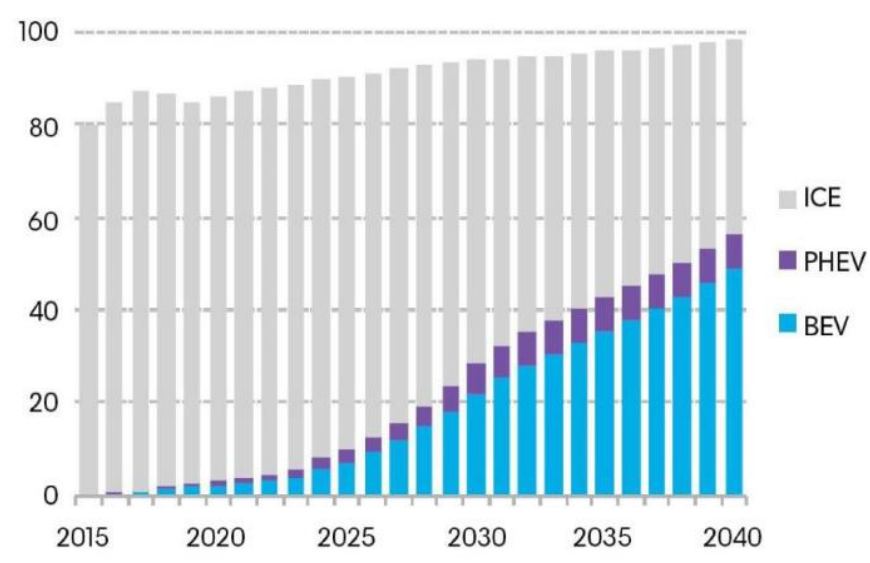

Source: BloombergNEF

The Chinese market remained world's largest electric car market with nearly 1.1 million electric cars sold in 2018 and, with 2.3 million units, it accounted for almost half of the global electric car stock. It expanded by 72 percent in 2017 , which solidified China's leadership position in EV sales. The country now has a larger EV market, primarily BEVs than Europe and the United States combined. With a sales share of around 94 percent, domestic OEMs currently dominate the Chinese EV market.

It was followed by Europe with 1.2 million electric cars and the United States of America with 1.1 million on the road by the end of 2018 and market growth of 385000 and 361000 electric cars from 2017.Norway was the global leader in terms of electric car market share at $46 \%$ of its new electric car sales in 2018, more than double the second-largest market share in Iceland at $17 \%$ and six-times higher than the third-highest Sweden at $8 \%$. 


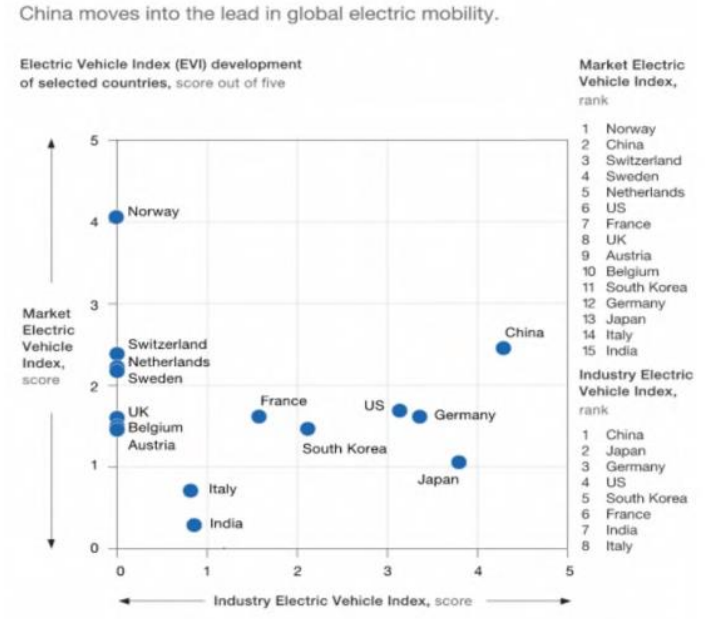

The amount of electric two/three-wheelers on the road was about 300 million by the end of 2018. The vast majority were in China. With sales in the tens of millions per year, the Chinese market for electric two-wheelers is hundreds of times larger than anywhere else in the world. In 2018, electric buses continued to witness dynamic developments, with more than 460,000 vehicles on the roads, almost 100000 more than in 2017. "Free floating" electric foot scooters raised very rapidly in 2018 and early 2019 in major cities around the world. These foot scooter schemes now operate in around 129 cities in the United States, 30 in Europe, 7 in Asia and 6 in Australia and New Zealand. Low-speed electric vehicles (LSEVs)* in 2018 were estimated at 5 million units, which was around 700,000 more units from 2017. All LSEVs were located in China.

India is new to the Electric Vehicle Industry. Both EV market acceptance and EV industry dynamics are at an early stage: the EV-adoption rate is less than 1 percent and domestic vehicle manufacturers are just starting to launch EV models. Although the government rolled out a new tax policy to encourage EV adoption, a clear strategic road map is still missing. Demand comes mainly from commercial owners and the public sector, and the country has almost no charging infrastructure. Since India's carbon-dioxide levels from electricity generation are among the world's highest, it also needs more renewable-energy sources for its EVs to achieve true "well-to-wheel" zero-emission status.

\section{CURRENT POLICIES}

All the governments in the world are approaching policies to promote the deployment of EVs, initially starting with a vision and setting targets. The root step is the adoption of electric vehicle and developing required infrastructure. Automakers are stimulated by procurement programmes which also help to kick-start the demand to increase the availability of EVs on the market, plus provide impetus for an initial roll out of publicly accessible charging infrastructure. Governments also provide economic incentives, particularly to bridge the cost gap between EVs and less expensive internal combustion engine (ICE) vehicles as well as to spur the early deployment of charging infrastructure. Economic incentives are often coupled with other policy measures that increase the value proposition of EVs (such as waivers to access restrictions, lower toll or parking fees) which are often based on the better performance of EVs in terms of local air pollution. Measures that provide crucial incentives to scale up the availability of vehicles with low and zero tailpipe emissions include fuel economy standards, zero-emission vehicle mandates and the rise in the ambition of public procurement programmes. Regulatory measures related to charging infrastructure include minimum requirements to ensure "EV readiness" in new or refurbished buildings and parking lots, deployment of publicly accessible chargers in cities and on highway networks, and are complemented by requirements regarding inter-operatibility and minimum availability levels for publicly accessible charging infrastructure. So far only observed in Norway, when the EV and charging infrastructure deployment evolves, some policy measures may need to be adjusted as the markets and infrastructure mature. One example is how fuel and vehicle taxes are adjusted and their contribution to government revenue.

Countries ahead in the race such as those involved in the Electric Vehicle Initiative are making significant progress from their commencing steps of EV policy implementation. Few of the steps involve establishment of standards, public procurement and early charging roll out, economic incentives. Many of these countries have regulatory instruments in place and, to-date, some advanced markets like Norway have started phasing out some aspects of their EV support policies.

\section{EV-RELATED POLICIES}

- The European Union has approved several important policies in the last half decade. Some of them include providing financial support by making nonreimbursable grants from Connecting Europe Facility(CEF) for development of charging infrastructure, support to projects focusing on research and innovation in electric mobility from the EU's Horizon 2020 or the European Investment Bank, incentives to encourage the purchase and use of EVs.

- The Government of India has approved phase-II of Faster Adoption and Manufacturing of Electric Vehicles in India (Fame India) scheme encouraging the faster adoption of electric and hybrid vehicles by offering incentives on purchase of electric vehicles and also by way of establishing necessary charging infrastructure for $\mathrm{EV}$ s.

- Japan, through collaboration between government , automakers and material suppliers, aims to reduce its greenhouse gas emissions by around $80 \%$ per vehicle, including around $90 \%$ reductions per passenger vehicle and electrifying every vehicle produced by Japanese automaker by 2050 .

- China has committed to relaxing its foreign investment requirements in the automobile industry to create a more competitive market for Chinese automakers. China has recently launched a dualcredit regulatory system which rewards or penalizes manufacturers with positive or negative credits based on their car models' fuel consumption and driving range. 
- The Government of Korea provides a plethora of incentives for Ev owners to increase the sale of EVs, some of which include reduction of highway toll up to $50 \%$, public parking discounts, exemption from electricity base fee and discounted rapid charge rate. Also, the government is planning to keep up the subsidies hor hydrogen and electric vehicles by 2022.

Countries such as Chile are seeing growth on the policy front. Chile has one of the largest fleet of electric buses after China. It aims to electrify its public transport by $100 \%$ by 2040 and $40 \%$ of private transport by 2050 . New Zealand too aims of going all electric by 2050 .

\section{TABLE I. EV Purchase Subsidies}

Denmark and Norway offer some of the highest electric-vehicle (EV) purchase subsidies.

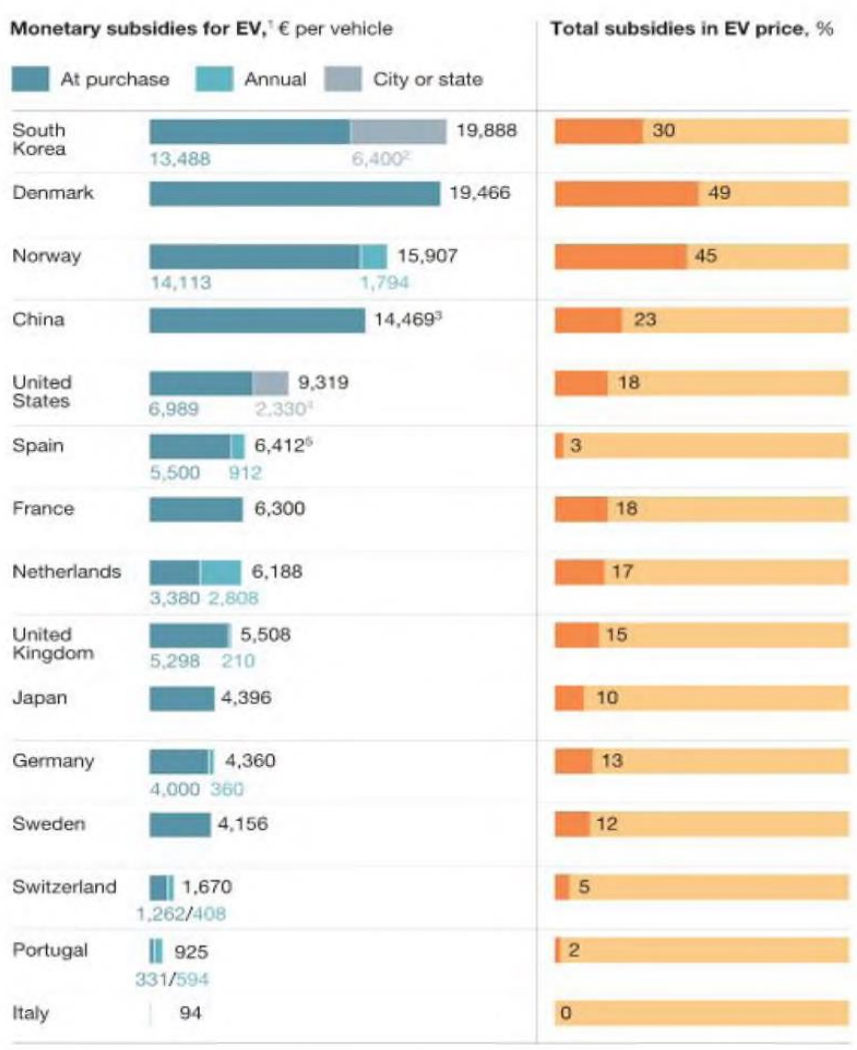

V. TECHNOLOGICAL DEVELOPMENTS

Advancements by manufacturers are bringing the latest crop of electric vehicles to the point where they are starting to overcome the four factors which have been repeatedly pointed; cost to buy, range, recharging and the time required for recharging. Not only the cost is likely to reduce, but it is highly dependent on the undergoing developments in the automotive sector, i.e. modification in battery chemistry, energy density and size of battery sizes and the scale of manufacturing industries.

Major developments to deduct the cost include optimization of the vehicle manufacturing platforms to take advantage of the simpler and innovative design architecture and taking advantage of the fewer moving parts than that of ICE vehicles.
Following the dedicated, scalable platform route, VW group intends to manufacture EVs of all sizes using many of the same parts so it can make the e-models profitable. Adapting battery sizes to match the range of vehicles to consumer travel habits is also important to avoid the oversizing of batteries in vehicles. Global automakers are establishing partnerships to develop EVs in order to meet range, passenger capacity and the boot space requirements for vehicles used in shared passenger fleet. OEMs have started consistently applying design-to-cost in particular to the EVs powertrain and bodyin-white design. The DTC focus has been mostly on the component integration in the powertrain area and smarter USA of lightweight materials in structural parts.

Technological progress has been seen for chargers because of increase in interest in EVs for heavy-duty vehicles such as trucks and buses. As the longer range EVs become more affordable, 'ultra-fast charging' is expected to allow EVs to add 300 kilometers of range in five to ten minutes. Longer range electric freight vehicles will be the prime users of this technology though the electrification path is still unclear. Standards have been made for ultra-fast chargers between 150-350 kilowatts which will reduce the typical charging time to 5-20 minutes.

Electric car manufacturers have been eager for a battery breakthrough that will improve the range of the vehicles as well as the life of the battery itself. Startup companies such as Innolith have been developing the high-density lithium-ion batteries that can solve both the above problems. The company claims to have developed the world's first 1000 watt-hours per kilogram $(\mathrm{Wh} / \mathrm{kg})$. The Tesla Model 3 uses 2170 cells batteries are $250 \mathrm{Wh} / \mathrm{kg}$. A battery with that density is capable for running an electric car for 1000 kilometers on a single charge. Tesla's batteries can support 531 kilometers of range in its most top of the line models.

TABLE II. Vehicle-Weight Evaluation.

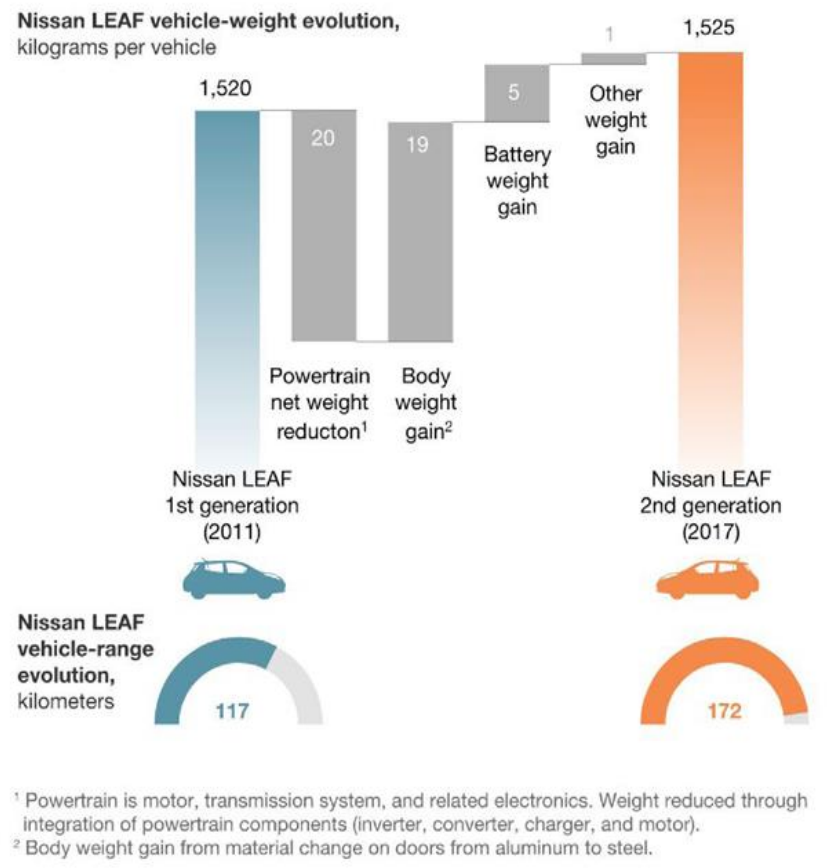




\section{CHALLENGES FACED AT CURRENT SITUATION}

The auto manufacturers are making progress in developing EVs with higher range, more power and high styling. The industry still needs to overcome plethora of challenges to accelerate the growth of EVs in a sustainable way.

- Lack of public, fast charging infrastructure is one of the main reasons people are reluctant to buy EVs. Although many BEVs can be charged at home, public fast charging infrastructure is important for owners who are travelling for long distances and also for those who cannot charge their EVs at home. There are only 16000 public charging stations in United States which is seven times less than gas stations. Less than 2000 of those provide fast charging as they are expensive and less profitable owing to too few transactions to break even. People will be reluctant to buy a EV unless they are assured of enough charging stations to recharge their EV if they run out of juice. But unless more EVs are sold, it will not be profitable to build a charging station.

- Another major concern is the compression of the profits due to EVs and other advanced technology for the automotive original equipment manufacturers(OEM). The amount of investment in the development of EVs is ramping each year and increasing losses are tied to negative margins for most EV models. However, these can be overcome by redesigning the platforms on which the EVs manufactured and working in collaborations with other manufacturers.

- The increase in use of electric vehicles and production of batteries imply increase in demand of new raw materials. As advances in battery are made, the type of raw materials will also vary according the battery chemistries. The automotive sector needs to anticipate and manage potential challenges and ensure the sustainability of supply chains. The main challenges faced with respect to the raw material supply include:

1) Ramp-up production, associated with the availability of raw materials, reasons for price spikes such as lack of synchronization between demand and supply and geographic concentration of extraction and refining.

2) Environmental impacts such as $\mathrm{CO} 2$ emissions related to supply chains, destruction of land, local pollution and impacts on local ecosystems.

3) Social issues which affect the living of local communities by mining operations.

\section{CONSIDERATION OF POLICIES/CONCLUSION}

- Increasing policy support for the optimization of battery industry value chain and establishing a policy framework that reduces investment risks is essential for the development of battery industry value chain. The governments should also focus on increasing the capacity and investments with major stakeholders Also, the gap between the academic institutions and training centers and the battery industry needs to close.

- The increase in demand of raw materials for EVs batteries demands attention for the supply of raw materials. To overcome the critical issues in the supply chains of the raw materials, governments need to figure out how to improve their transparency.

- The policies developed by the countries should aim on establishing a path and set of targets along with the adoption of vehicle and charging standards.

- The economic incentives motivate people to buy EVs especially as long as the prices of EVs are higher than that of internal combustion engine vehicles. The same applies for setting up the charging infrastructure.

- The deployment of public charging stations on highways and in cities are also crucial in increasing the adoption of EVs and boosting consumer confidence.

- Procurement programmes are important to start demand for EVs and encourage the automakers to increase their production. They also help to enable an initial roll-out of the public charging infrastructure.

\section{REFERENCES}

[1] Rony Argueta "A Technical Research Report: The Electric Vehicle."March 11,2010. University of California Santa Barbara College of Engineering.

[2] Seungyoung Ahn, Joungho Kim "Magnetic field design for high efficient and low EMF wireless power transfer in on-line electric vehicle". 31 May 2011 IEEE.

[3] kejun Qian, Chengke Zhou "Temperature effect on electric vehicle battery cycle life in Vehicle-to-grid applications" 22 March 2011 IEEE.

[4] Shikha Rokadiya, Anup Bandivadekar "Hybrid and Electric Vehicles In India Current scenario and Market Incentives." December 2016 ICCT Report Working Paper.

[5] Michael Beliveau, James Rehberger "A Study on Hybrid Cars: Environmental Effects and Consumer Habits." : 28 April 2010 Report By Worcester Polytechnic Institute.

[6] K.V. Vidyanandan "Overview of Electric and Hybrid Vehicles" March 2018.

[7] Global EV Outlook (2019);www.iea.org/publications/reports/globalevoutlook2019/

[8] The global electric-vehicle market is amped up and on the rise (McKinsey

Company);https://www.mckinsey.com/industries/automotive-andassembly/ourinsights/the-global-electric-vehicle-market-is-amped-upand-on-the-rise

[9] Expanding electric-vehicle adoption despite early growing pains (McKinsey

Company);https://www.mckinsey.com/industries/automotive-andassembly/our-insights/expanding-electric-vehicle-adoption-despiteearly-growing-pains

[10] FAME India Scheme Phase 2 (National Automotive Board);http://fame2.heavyindustry.gov.in/content/english/15_1_FAME I.aspx

[11] Electric Cars in Korea https://kojects.com/2019/07/03/electric-cars-inkorea/ 